\title{
Synthesis and Properties of Nanoparticle $\mathrm{Li}\left[\mathrm{Li}_{0.2} \mathrm{Mn}_{0.54} \mathrm{Ni}_{0.13} \mathrm{Co}_{0.13}\right] \mathrm{O}_{2}$ Cathode Material by Coprecipitation Method with Non-aqueous Medium
}

\author{
LIIU Ling ${ }^{1, \mathrm{a}}$ and GUAN Chang ${ }^{1, \mathrm{~b}}$ \\ ${ }^{1}$ College of Petrochemical Engineering, Jilin Institute of Chemical Technology, Jilin 132022, China \\ a1liuhit@163.com, ${ }^{\mathrm{b}}$ guanch001@163.com
}

\begin{abstract}
The nanoparticle $\mathrm{Li}\left[\mathrm{Li}_{0.2} \mathrm{Mn}_{0.54} \mathrm{Ni}_{0.13} \mathrm{Co}_{0.13}\right] \mathrm{O}_{2}$ powder was synthesized via co-precipitation method in non-aqueous system. The structure, morphology and electrochemical behaviors of the synthesized material were characterized by X-ray diffraction (XRD), scanning electron microscope (SEM) and galvanostatic charge-discharge tests. XRD pattern revealed that the nanosize $\mathrm{Li}\left[\mathrm{Li}_{0.2} \mathrm{Mn}_{0.54} \mathrm{Ni}_{0.13} \mathrm{Co}_{0.13}\right] \mathrm{O}_{2}$ powders had layered hexagonal structure with low cation mixing. SEM image exhibited the nanoparticles were synthesized via non-aqueous coprecipitaiton method. And galvanostatic charge-discharge tests comfirmed the $\mathrm{Li}\left[\mathrm{Li}_{0.2} \mathrm{Mn}_{0.54} \mathrm{Ni}_{0.13} \mathrm{Co}_{0.13}\right] \mathrm{O}_{2}$ electrode had good electrochemical properties, especially the high rate discharge capability such as $10 C$, which make it meet the requirement for high power application such as EV or HEV.
\end{abstract}

Keywords: $\mathrm{Li}\left[\mathrm{Li}_{0.2} \mathrm{Mn}_{0.54} \mathrm{Ni}_{0.13} \mathrm{Co}_{0.13}\right] \mathrm{O}_{2}$, nanoparticle, high rate

\section{Introduction}

Lithium ion batteris (LIB) have become an important power source for portable electronic devices, such as cellular phones and laptop computers [1]. However, the poor high rate capability of LIB withdraws its further use in high power applications [2,3]. Now commercial LIB mostly rely on lithium transition metal oxide, such as $\mathrm{LiCoO}_{2}, \mathrm{LiNiO}_{2}$, and $\mathrm{LiMn}_{2} \mathrm{O}_{4}$ [4-6]. However, some issues including safty, toxicity and cost of these materials inhibit their further use in price sensitive and large-scale applications, such as hybrid electric vehicles. Thus, extensive research has been carried out over the past ten years to find alternative materials with the low cost, long life and high capacity.

Recently, the Li-rich cathode materials, solid solutions between $\mathrm{Li}\left[\mathrm{Li}_{1 / 3} \mathrm{Mn}_{2 / 3}\right] \mathrm{O}_{2}$ and $\mathrm{LiMO}_{2}(\mathrm{M}=\mathrm{Mn}, \mathrm{Co}$, and $\mathrm{Ni})$ have been found to be the most attractive cathode material for lithium ion batteries because of high discharge capacity and low cost compared to the popularly used $\mathrm{LiCoO}_{2}$. However, there are several intrinsic defects hindering their extensive commercial application, such as the high irreversible capacity loss in the initial cycle and low rate capability. Besides the high discharge capacity, long cycling life and safety, the high rate capability is the most important properties for high power applications. For lithium ion 
batteries, the maximum rate of lithium ion diffusion in the solid state is limited, thus its high rate capability is also limited. Decreasing the particle size and extending its surface area are the ideal way to reduce the lithium ion diffusion distance and increase the activity of the electrode. Therefore, nanoparticle electrode is often used in lithium ion batteries for high power applications.

However, synthesizing the lithium metal oxide particles with a size of nanometer is very hard. The widely adoption choice of solid state or water medium coprecipitation method can give uniform, homogeneous and phase-pure oxide products, but the large particles with the size of micrometer withdraw its use in nanoparticle production $[7,8]$. In order to prepare nanosized particles for lithium metal oxide, we tried the used coprecipitation method with nonaqueous medium, and the pure $\mathrm{Li}\left[\mathrm{Li}_{0.2} \mathrm{Mn}_{0.54} \mathrm{Ni}_{0.13} \mathrm{Co}_{0.13}\right] \mathrm{O}_{2}$ with nanosize particles has been synthesized. In this paper, this novel nonaqueous coprecipitation method is reported and the structure, morphology and electrochemical properties of the obtained nanoparticles were studied in detail.

\section{Experimental}

\subsection{Synthesis of nanosize Li[Li0.2Mn0.54Ni0.13Co0.13]O2 particles}

The nanosize $\mathrm{Li}\left[\mathrm{Li}_{0.2} \mathrm{Mn}_{0.54} \mathrm{Ni}_{0.13} \mathrm{Co}_{0.13}\right] \mathrm{O}_{2}$ particles was prepared by coprecipitation in ethanol solution with vigorous mechanical stirring. $\mathrm{LiNO}_{3}, \mathrm{Ni}\left(\mathrm{NO}_{3}\right)_{2}, \mathrm{Co}\left(\mathrm{NO}_{3}\right)_{2}$ and $\mathrm{MnCl}_{2}$ are dissolved in ethanol with the mole ratio of 1.9: 0.54:0.13:0.13. The total mole concentration is $1 \mathrm{M}$. The solution was dropped into $\mathrm{KOH}$ ethanol solution at a speed of one drop per second with vigorous stirring. The precipitate was separated from the solution and dried at $80^{\circ} \mathrm{C}$ for $12 \mathrm{~h}$. The deposit was grinded with ball mill for $6 \mathrm{~h}$, and then it was pressed into pellets. The pellets were calcined at $600{ }^{\circ} \mathrm{C}$ for $6 \mathrm{~h}$, and then they were reground. Finally, pellets were remade and calcined at $800{ }^{\circ} \mathrm{C}$ for $3 \mathrm{~h}$.

\subsection{Measurements}

Powder X-ray diffraction (XRD, D/max-IIB, Rigaku, Japan) employing $\mathrm{Cu} \mathrm{K} \alpha$ radiation was used to identify the crystalline phase of the prepared powders. The surface morphologies of the powders were observed with a scanning electron microscope (SEM, S-4700, HITACHI, Japan). In order to determined the chemical composition of the prepared material, atomic absorption spectroscopy (AAS, AAnalyst200, PE, USA) was carried out.

The charge and discharge characteristics of $\mathrm{Li}\left[\mathrm{Li}_{0.2} \mathrm{Mn}_{0.54} \mathrm{Ni}_{0.13} \mathrm{Co}_{0.13}\right] \mathrm{O}_{2}$ cathodes were examined in CR2032 coin-type half-cell. Cells were composed of a cathode and a lithium metal anode separated by a porous polypropylene film. Composite cathode was prepared by thoroughly mixing the active material $(80 \%)$ with carbon black $(10 \%)$, and polyvinylidene fluoride $(10 \%)$ in N-methyl-pyrrolidinone. The slurry was then cast on an aluminum foil and dried at $90{ }^{\circ} \mathrm{C}$ for $10 \mathrm{~h}$ in vacuum. Disks were then punched out of the foil. The electrolyte solution was 1M LiPF6 in a mixture of ethylene carbonate (EC) and dimethyl carbonate (DMC) with a volume ratio of $1: 1$. The coin cell was assembled in an argon-filled glove box (Braun, Germany). Galvaostatic experiments were carried out with a Battery Testing System(Arbin, USA). 


\section{Results and Discussions}

\subsection{Structure Analysis}

In order to characterize the chemical composition of the nanoparticle material, the AAS analysis was employed. And the AAS result shows the atom ratio of Li: $\mathrm{Mn}: \mathrm{Ni}$ : $\mathrm{Co}$ is 1.2: 0.54:0.14:0.13, which is equal to the designed composition of $\mathrm{Li}\left[\mathrm{Li} i_{0.2} \mathrm{Mn}_{0.54} \mathrm{Ni}_{0.13} \mathrm{Co}_{0.13}\right] \mathrm{O}_{2}$.

XRD pattern of the prepared $\mathrm{Li}\left[\mathrm{Li}_{0.2} \mathrm{Mn}_{0.54} \mathrm{Ni}_{0.13} \mathrm{Co}_{0.13}\right] \mathrm{O}_{2}$ powder is shown in Figure 1. Except the super lattice peaks between $20^{\circ}$ and $25^{\circ}$, the other peaks of the XRD patterns could be indexed based on the $\alpha-\mathrm{NaFeO} 2$ structure with space group $R-3 m$. The weak peaks between $20^{\circ}$ and $25^{\circ}$ are consistent with the $\mathrm{LiMn}_{6}$ cation arrangement that occurs in the transition metal layers of $\mathrm{Li}_{2} \mathrm{MnO}_{3}$ regions or nano-domains, which can be indexed to the monoclinic unit cell $\mathrm{C} 2 / \mathrm{m}$ [9]. No peak for any impurity phase is observed in the pattern, indicating the high purity of the prepared material. In the XRD pattern, the integrated peak splits of $(006) /(102)$ and $(018) /(110)$ are known to be an indictor of layered structure [10]. As seen in the figure, clear peak splits of $(006) /(102)$ and $(018) /(110)$ are observed, which indicated the formation of highly ordered layer structure for $\mathrm{Li}\left[\mathrm{Li} \mathrm{i}_{0.2} \mathrm{Mn}_{0.54} \mathrm{Ni}_{0.13} \mathrm{Co}_{0.13}\right] \mathrm{O}_{2}$.

In $\mathrm{Li}\left[\mathrm{Li}_{0.2} \mathrm{Mn}_{0.54} \mathrm{Ni}_{0.13} \mathrm{Co}_{0.13}\right] \mathrm{O}_{2}$, the radius of $\mathrm{Ni}^{2+}$ is close to that of $\mathrm{Li}^{+}$. A partial interchange of occupancy of $\mathrm{Li}$ and transition metal ions among the sites would give rise to disordering in the structure called 'cation mixing'. Cation mixing is known to deteriorate the electrochemical performance of the above layered compound. The integrated intensity ratio of $I 003 / I 104(R)$ is sensitive to the cation mixing $[11,12]$. Researchers often used high intensity ratio of $I 003 / I 104(R)$ to indicate the cation mixing of the layered structure [13]. Generally, $R<1.2$ is an indication of undesirable cation mixing [14]. A value of $R=1 \mathrm{mAg}^{-1}$ $(0.2 C)$ between 2.0 and $4.6 \mathrm{~V}$ is shown in Figure 4. The discharge capacity deteriorates slightly during cycles and the coulombic efficiencies of the subsequent cycles are all above $96 \%$, expect the first cycle. The material exhibits stable cycle property and $96.3 \%$ of the initial discharge capacity is retained after 50 cycles.

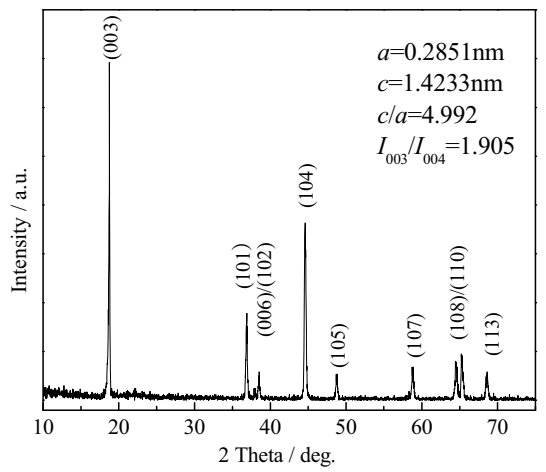

Figure 1 XRD pattern of the nanometric $\mathrm{Li}\left[\mathrm{Li}_{0.2} \mathrm{Mn}_{0.54} \mathrm{Ni}_{0.13} \mathrm{Co}_{0.13}\right] \mathrm{O}_{2}$ powder with the lattice parameter as an insert

Although the above results demonstrate the good electrochemical performance at moderate rates, the importance of high power applications encourages the investigation on the high rate performance of these materials. Figure 5 shows the discharge capacities of the electrode with $\mathrm{Li}\left[\mathrm{Li}_{0.2} \mathrm{Mn}_{0.54} \mathrm{Ni}_{0.13} \mathrm{Co}_{0.13}\right] \mathrm{O}_{2}$ powders as active material at different discharge rate between 2.0 and $4.6 \mathrm{~V}$. The nanoparticle electrode exhibited excellent properties both at moderate and at high rate capacities, such as $10 \mathrm{C}$. The good rate capability of the nanosize 
materials may be due to their decreasing particle size and improving the morphology. For the material prepared by conventional hydroxide coprecipitation, the specific surface area and porosity is lower due to its larger particle size. During high current charge and discharge, the Li ion in bulk lattice cannot diffuse or transfer to the surface in time because of the long diffusion path, which result in lower capacity. However, for the nanomaterial, the area of the interface between the electrolyte and the active material is very large and the diffusion path of lithium ion from bulk to surface is short. Therefore, the prepared nanosize $\mathrm{Li}\left[\mathrm{Li}_{0.2} \mathrm{Mn}_{0.54} \mathrm{Ni}_{0.13} \mathrm{Co}_{0.13}\right] \mathrm{O}_{2}$ powder show superior high rate capablity..905was obtained for the prepared $\mathrm{Li}\left[\mathrm{Li}_{0.2} \mathrm{Mn}_{0.54} \mathrm{Ni}_{0.13} \mathrm{Co}_{0.13}\right] \mathrm{O}_{2}$, which indicated the low amount of cation mixing in the structure. Therefore, good electrochemical performance would be expected for the prepared $\mathrm{Li}\left[\mathrm{Li}_{0.2} \mathrm{Mn}_{0.54} \mathrm{Ni}_{0.13} \mathrm{Co}_{0.13}\right] \mathrm{O}_{2}$.

The lattice parameters were obtained from the XRD data and the results were summarized in Figure 1. The lattice parameter, $a$, is related to average metal-metal intra-slab distance; the lattice parameter, $c$, is related to the average metal-metal inter-slab distance; and the trigonal distortion, $c / a$, is related to the hexagonal structure disorder [14]. For layered compounds, higher value of $c / a$ is desirable for better hexagonal structure [15]. The hexagonal lattice parameter of the prepared $\mathrm{Li}\left[\mathrm{Li}_{0.2} \mathrm{Mn}_{0.54} \mathrm{Ni}_{0.13} \mathrm{Co}_{0.13}\right] \mathrm{O}_{2}$ were determined to be $a=0.2851 \mathrm{~nm}$ and $c=1.4233 \mathrm{~nm}$. These data match well with the values observed by other reports $[16,17]$. The value of $c / a=4.992$ reveals that the well defined hexagonal structure is formed. All the above results confirm that the prepared $\mathrm{Li}\left[\mathrm{Li}_{0.2} \mathrm{Mn}_{0.54} \mathrm{Ni}_{0.13} \mathrm{Co}_{0.13}\right] \mathrm{O}_{2}$ powder have well defined layered hexagonal structure.

\subsection{Morphology of the Particles}

Figure 2 shows the SEM image of $\mathrm{Li}\left[\mathrm{Li}_{0.2} \mathrm{Mn}_{0.54} \mathrm{Ni}_{0.13} \mathrm{Co}_{0.13}\right] \mathrm{O}_{2}$ powder.

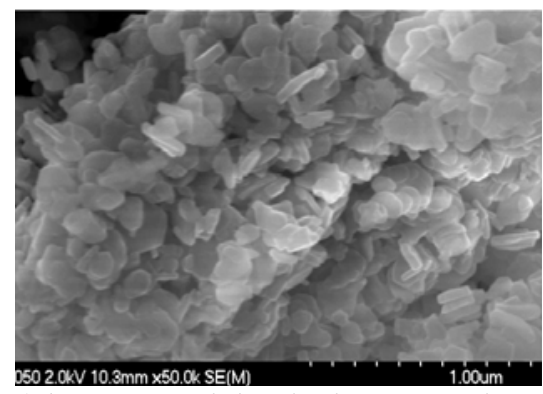

Figure 2 SEM images of the nanoparticle $\mathrm{Li}\left[\mathrm{Li}_{0.2} \mathrm{Mn}_{0.54} \mathrm{Ni}_{0.13} \mathrm{Co}_{0.13}\right] \mathrm{O}_{2}$ synthesized via non-aqueous coprecipitiation method

Most of the particles have the shape of thin platelets with the particle size of nanometer. The thickness of the platelets is about $30 \mathrm{~nm}$, and the lateral length of the platelets is in the range of $100 \sim 150 \mathrm{~nm}$. The shape of the prepared $\mathrm{Li}\left[\mathrm{Li}_{0.2} \mathrm{Mn}_{0.54} \mathrm{Ni}_{0.13} \mathrm{Co}_{0.13}\right] \mathrm{O}_{2}$ is quite different from the shape of $\mathrm{Li}\left[\mathrm{Li}_{0.2} \mathrm{Mn}_{0.54} \mathrm{Ni}_{0.13} \mathrm{Co}_{0.13}\right] \mathrm{O}_{2}$ prepared by hydroxide coprecipitation which usually is spherical or a short stick.

\subsection{Electrochemical Properties}

The initial charge and discharge curves of the electrode with powders as active material at $0.2 C$ are presented in Figure 3. The first charge and discharge capacity between 2.0 and 4.6 $\mathrm{V}$ are 317.17 and $244.95 \mathrm{mAhg}^{-1}$ respectively. The irreversible capacity loss in the first cycle is $72.22 \mathrm{mAhg}^{-1}$ and the coulombic efficiency is $77.23 \%$. 


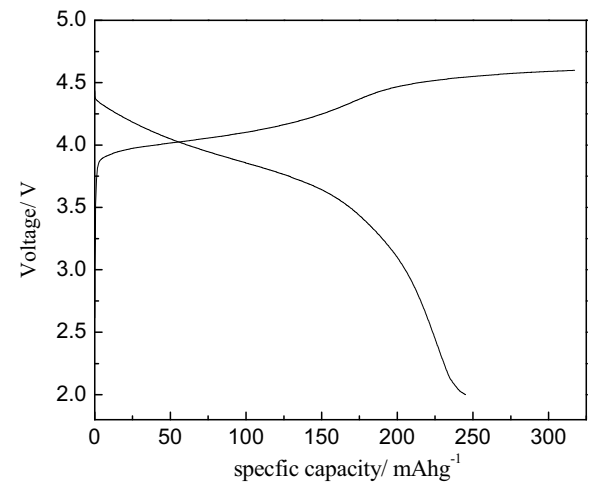

Figure 3 Initial charge and discharge curves of the $\mathrm{Li}\left[\mathrm{Li}_{0.2} \mathrm{Mn}_{0.54} \mathrm{Ni}_{0.13} \mathrm{Co}_{0.13}\right] \mathrm{O}_{2}$ electrode at $0.2 \mathrm{C}$

The charge and discharge curves of $\mathrm{Li}\left[\mathrm{Li}_{0.2} \mathrm{Mn}_{0.54} \mathrm{Ni}_{0.13} \mathrm{Co}_{0.13}\right] \mathrm{O}_{2}$ cathode at different cycles with a constant current density of $32 \mathrm{mAg}^{-1}(0.2 C)$ between 2.0 and $4.6 \mathrm{~V}$ is shown in Figure 4 . The discharge capacity deteriorates slightly during cycles and the coulombic efficiencies of the subsequent cycles are all above $96 \%$, expect the first cycle. The material exhibits stable cycle property and $96.3 \%$ of the initial discharge capacity is retained after 50 cycles.

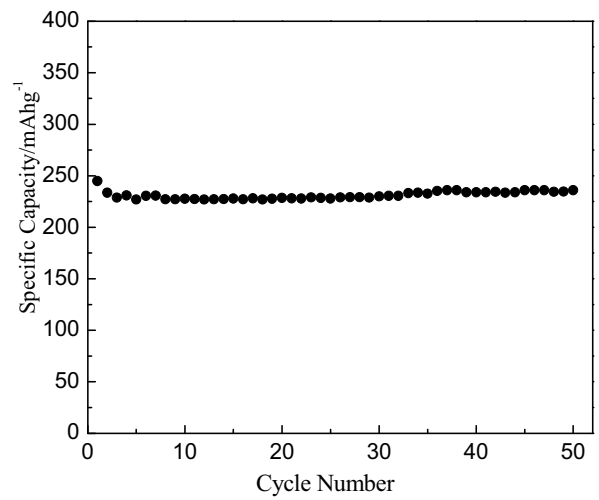

Figure 4 Cycle performances of nanoparticle $\mathrm{Li}\left[\mathrm{Li}_{0.2} \mathrm{Mn}_{0.54} \mathrm{Ni}_{0.13} \mathrm{Co}_{0.13}\right] \mathrm{O}_{2}$ electrode at the rate of $0.2 \mathrm{C}$

Although the above results demonstrate the good electrochemical performance at moderate rates, the importance of high power applications encourages the investigation on the high rate performance of these materials. Figure 5 shows the discharge capacities of the electrode with $\mathrm{Li}\left[\mathrm{Li}_{0.2} \mathrm{Mn}_{0.54} \mathrm{Ni}_{0.13} \mathrm{Co}_{0.13}\right] \mathrm{O}_{2}$ powders as active material at different discharge rate between 2.0 and $4.6 \mathrm{~V}$. The nanoparticle electrode exhibited excellent properties both at moderate and at high rate capacities, such as $10 \mathrm{C}$. The good rate capability of the nanosize materials may be due to their decreasing particle size and improving the morphology. For the material prepared by conventional hydroxide coprecipitation, the specific surface area and porosity is lower due to its larger particle size. During high current charge and discharge, the 
Li ion in bulk lattice cannot diffuse or transfer to the surface in time because of the long diffusion path, which result in lower capacity. However, for the nanomaterial, the area of the interface between the electrolyte and the active material is very large and the diffusion path of lithium ion from bulk to surface is short. Therefore, the prepared nanosize $\mathrm{Li}\left[\mathrm{Li}_{0.2} \mathrm{Mn}_{0.54} \mathrm{Ni}_{0.13} \mathrm{Co}_{0.13}\right] \mathrm{O}_{2}$ powder show superior high rate capablity.

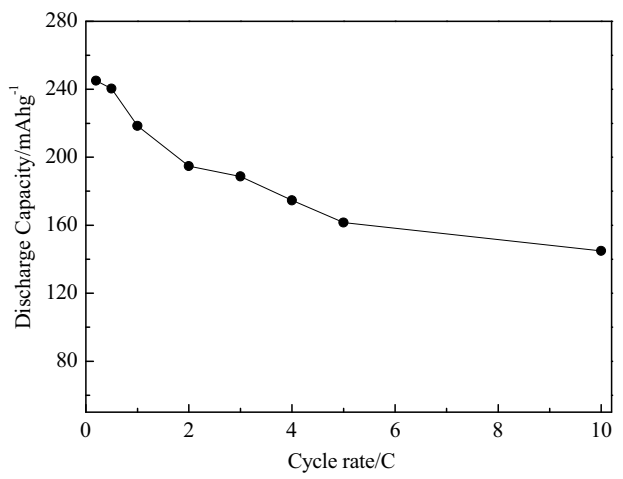

Figure 5 The discharge capacities of nanoparticle $\mathrm{Li}\left[\mathrm{Li}_{0.2} \mathrm{Mn}_{0.54} \mathrm{Ni}_{0.13} \mathrm{Co}_{0.13}\right] \mathrm{O}_{2}$ electrode at different discharge rate

\section{Summary}

The nanosize $\mathrm{Li}\left[\mathrm{Li}_{0.2} \mathrm{Mn}_{0.54} \mathrm{Ni}_{0.13} \mathrm{Co}_{0.13}\right] \mathrm{O}_{2}$ particles were synthesized via co-precipitation in non-aqueous system. The structure, morphology and electrochemical performances were characterized by XRD, SEM and galvaostatic charge-discharge tests. XRD analysis revealed a well defined hexagonal structure with low amount of cation mixing. SEM image showed the synthesized material had shape of platelets with the particle size of about 100 150 nm. The prepared nanomaterial has good electrochemical properties and superior high rate capability, which meets the requirement of high power applications such as EV and HEV.

\section{References}

1. K. Mizushima, P. C. Jones, P. J.Wiseman, J. B. Goodenough, Mater. Res. Bull 15 (1980) 783.

2. A. M. Andersson, D. P. Abraham, R. Haasch, S. Maclaren, J. Liu, K. Amine, J. Electrochem. Soc. 149 (2002) A1358.

3. K. Amine, C. H. Chen, J. Liu, M. Hammond, A. Jansen, D. Dees, I. Bloom, D. Vissers, G. Henriksen, J. Power Sources 97-98 (2001) 684.

4. S.H. Park, C.S. Yoon, S.G. Kang, H.S. Kim, S.I. Moon, Y.K. Sun, Electrochim. Acta 49 (2004) 557.

5. N. Yabuuchi, Y. Koyama, N. Nakayama, T. Ohzuku, J. Electrochem. Soc. 152(2005) A1434.

6. K.M. Shaju, G.V. Subba Rao, B.V.R. Chowdari, J. Electrochem. Soc. 151 (2004)A1324.

7. M. H. Lee, Y. J. Kang, S. T. Myung, Y.K. Sun, Electrochim. Acta 50(2004)939.

8. T. H. Cho, S. M. Park, M. Yoshio, T. Hirai, Y. Hideshima, J. Power Sources $142(2005) 360$. 
9. J. S. Kim, C. S. Johnson, J. T. Vaughey, Chemistry of Materials 16(2004)1996.

10. J. Cho, G. Kim, H. S. Lim, J. Electrochem. Soc. 146 (1999) 3571.

11. D. Li, T. Muta, L. Zhang, M. Yoshio, H. Noguchi, J. Power Sources 132 (2004) 150.

12. T. Ohzuku, A. Ueda, M. Nagayama, J. Electrochem. Soc. 140(1993) 1862.

13. Z. L. Liu, A. S. Yu, J. Y. Lee, J. Power Sources 81-82 (1999)416.

14. X. Luo, X. Wang, L. Liao, X. Wang, S. Gamboa, P. J. Sebastian, J. Power Sources 161(2006) 601.

15. X. Zhang, Z. Wen, X. Yang, X. Xu, J. Li, Mater. Research Bull. 41 (2006) 662.

16. D. Li, T. Muta, L. Zhang, M. Yoshio, H. Noguchi, J. Power Sources 132 (2004) 150.

17. X. Luo, X. Wang, L. Liao, S. Gamboa, P.J. Sebastian, J. Power Souces 158 (2006) 654. 